\title{
Preparation of polycrystalline tungsten nanofibers by needleless electrospinning
}

\author{
Vojtech Kundrat, Vit Vykoukal, Zdenek Moravec, Lucie Simonikova, Karel Novotny, Jiri Pinkas* \\ Department of Chemistry, Faculty of Science, Masaryk University, Kotlarska 2, CZ-61137 Brno, Czech Republic
}

\section{A R T I C L E I N F O}

\section{Article history:}

Received 2 July 2021

Received in revised form 26 December 2021

Accepted 29 December 2021

Available online 30 December 2021

\section{Keywords:}

Electrospinning

Tungsten

Metal

Silicotungstic Acid

Polyvinyl alcohol

Nanofibers

\begin{abstract}
A B S T R A C T
One-dimensional metal nanostructures are of great interest for applications in electronic and micromechanical devices, solar cells, sensors, and heterogeneous (photo)catalysts. We describe the multigram preparation method for nanoscopic tungsten fibers (diameter $107 \pm 49 \mathrm{~nm}$ ) for the first time. The material was prepared by needleless electrospinning from an aqueous polyvinyl alcohol and silicotungstic acid solution. A green fibrous composite mat was calcined in air to $\mathrm{WO}_{3} / \mathrm{SiO}_{2}$ fibers and further reduced in forming gas at various temperatures $\left(500-1000{ }^{\circ} \mathrm{C}\right)$. The reduction process proceeded from nanofibrous blue tungsten oxide to mixtures of reduced tungsten oxides with metallic tungsten and finally at $800{ }^{\circ} \mathrm{C}$ to pure metallic $\mathrm{W}$ in the form of polycrystalline fibers. These nanofibers consist of individual tungsten nanoparticles covered and interconnected by amorphous silica. All prepared materials were characterized by the TG-DSC, TG-DTA, SEM, TEM, STEM-EDS, and XRD methods. This optimized fabrication method could be scaled up to supply ample amounts of metallic tungsten nanofibers for future applications.
\end{abstract}

(c) 2021 Elsevier B.V. All rights reserved.

\section{Introduction}

Metallic nanorods, nanowires, and nanofibers attract intense attention for their interesting electronic, plasmonic, magnetic, mechanical, and thermal properties [1]. One of the exciting applications is in transparent conducting films. New transparent electrodes are crucial for the development of optoelectronic devices, organic lightemitting diodes, solar cells, transparent film heaters, flexible touch panels, and electromagnetic shielding based on their high electrical conductivity, transparency, and mechanical flexibility. Metallic nanowire-based percolating networks are studied as promising alternatives to indium-tin oxide (ITO) films [2]. The advantages of metallic nanowire films are their low cost, solution processability, and compatibility with flexible substrates for high throughput production by roll-to-roll or ink-printing techniques [3-6]. Another application area involves smart textiles that convert body heat, biomechanical, biochemical, and solar energy to electricity $[7,8]$. Such materials can also be used for sensing of body motion, pressure, temperature, and other physiological signal detection $[9,10]$. Construction of artificial muscles could take advantage of composites of thermoresponsive polymers with electrically resistive nanowires or arrays of nanowires of shape-memory alloys or magnetostrictive

\footnotetext{
* Corresponding author.

E-mail address: jpinkas@chemi.muni.cz (J. Pinkas).
}

materials [11]. Conductive metal nanowires covered with a shell of a catalytically active substance or alloyed with suitable elements are employed as heterogeneous catalysts with enhanced activity, selectivity, and stability. Their high surface area, anisotropic morphology, and unique electronic properties are utilized in catalyzing organic coupling and reduction reactions, as well as in electro- and photocatalytic reactions [12-16]. Electrodes constructed from metal nanowire arrays provide a continuous path for electron transport with improved conductivity and kinetics of the electrode reactions, short ion transport pathways, faster diffusion, and the ability to accommodate the volume changes in $\mathrm{Li}$ and $\mathrm{Na}$-ion batteries and capacitors $[17,18]$.

Compared to $\mathrm{Au}, \mathrm{Ag}, \mathrm{Cu}, \mathrm{Ni}, \mathrm{Co}, \mathrm{Pd}$, and $\mathrm{Pt}$, the tungsten nanowires are less studied. Metallic tungsten is a hard refractory element with extensive applications in material science and industrial processes. The primary utilization is found in producing alloys used in a broad spectrum of items $[19,20]$. Its manufacturability is limited by an extremely high melting point of $3422{ }^{\circ} \mathrm{C}$ [21]; therefore, powder metallurgy must be applied to obtain suitable products. Tungsten is studied in many chemical forms where oxides, carbide, and chalcogenides are in research focus due to usability in many application fields, such as chemical sensors, catalysts, electrodes, and photoactive materials [21-26].

Nanoscopic forms of metallic tungsten are intensively studied for their applications as sintered materials [27], single-cell thermocouple sensors [28], microelectronic devices [29], or nanoelectrodes 


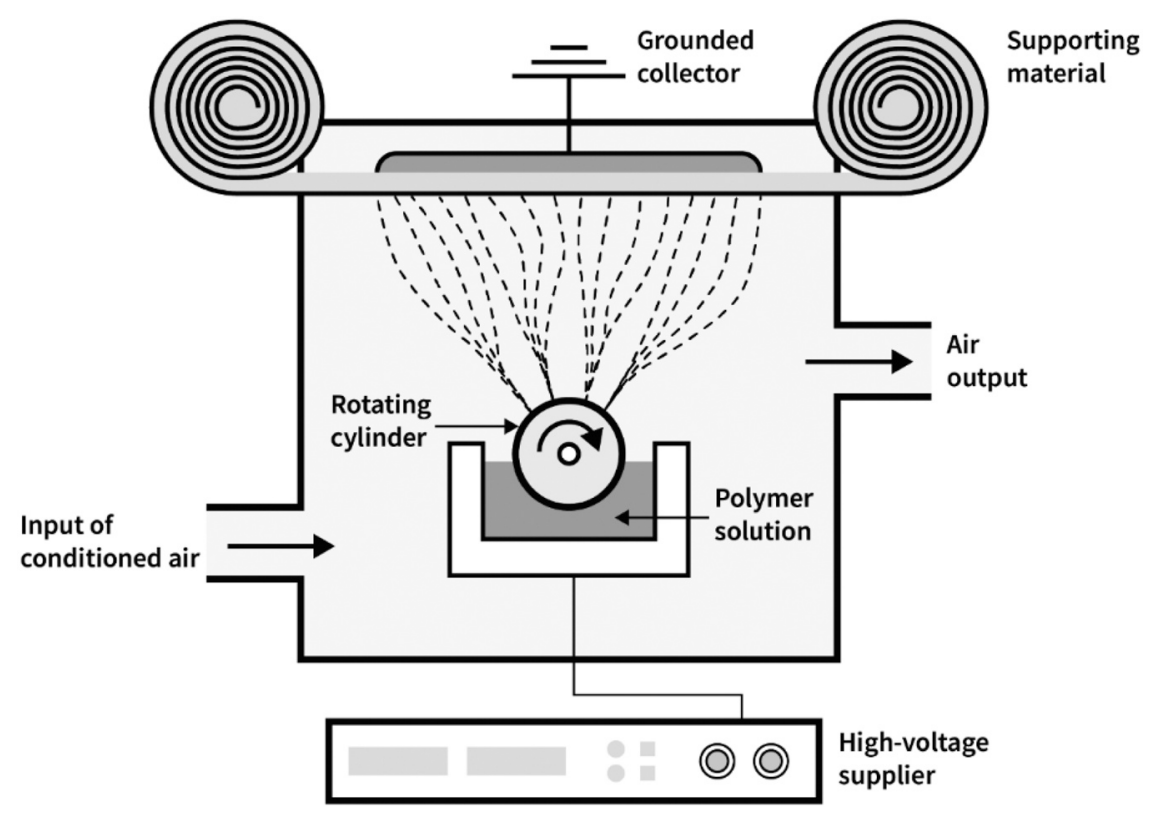

Fig. 1. Submerged electrode equipped with microblades in Nanospider NS LAB500S [57].

[30]. The most explored nanoscopic morphology of $\mathrm{W}$ are nanoparticles in many forms prepared by an array of different methods, such as the electric explosion of a wire [31], solvothermal decomposition of $\mathrm{W}(\mathrm{CO})_{6}$ [32], salt-assisted combustion reaction using $\mathrm{Mg}$ or $\mathrm{Zn}$-based reduction or reducing salts (e.g., $\mathrm{NaBH}_{4}$ ) [33], reduction of tungsten oxide nanoneedles in $\mathrm{H}_{2}$ [34], and $\mathrm{Ar} / \mathrm{H}_{2}$ plasma reduction of ammonium paratungstate powder [35].

Tungsten nanowires are another type of morphology. They are produced by a range of methods, including the hard templating by mesoporous silica SBA-15 [36] or mesoporous carbon [37], the chemical vapor transport process from $\mathrm{W}$ filament [38], Ni-catalyzed vapor-phase decomposition of $\mathrm{WO}_{2}(\mathrm{OH})_{2}[39,40]$, decomposition of $\mathrm{W}(\mathrm{CO})_{6}$ or $\mathrm{WF}_{6}$ by a focused ion beam [41,42], electric field [43,44], and an electron beam [45-47], carbothermal reduction of $\mathrm{WO}_{3} / \mathrm{CTAB}$ lamellar composites [48], and especially by directional solidification and selective electrochemical dissolution of NiAl-W eutectic alloys $[49,50]$ resulting in single-crystalline nanowires with extraordinary lengths and diameters around $200 \mathrm{~nm}$.

The current synthetic methods produce only individual $W$ nanowires, use toxic precursors, or waste large amounts of costly template or matrix materials. Thus, there is a clear need for a simple high-yield method producing ultrafine polycrystalline $\mathrm{W}$ fibers on a gram scale. Electrospinning is a standard method of preparing fibers with a diameter of less than one micrometer. It is mainly used in laboratories in the form of small-scale needle-based devices [51-53]. For this study, we have chosen needleless electrospinning [54] as a method that can be expanded to the industrial production scale [55]. The industrialization of the process was facilitated by the introduction of electrospinning from a free surface, where multiple electrospinning jets are formed, and a large continuous sheet of nonwoven, unoriented nanofibers is produced. One of several commercially available devices is Nanospider from the Czech company Elmarco which operates with a submerged rotating cylinder electrode (Fig. 1). In laboratory-scale electrospinning, the high voltage

Table 1

Properties of electrospinning solutions.

\begin{tabular}{ll}
\hline Dynamic viscosity $[\mathrm{mPa} \mathrm{s}]\left(21.6^{\circ} \mathrm{C}\right)$ & 258 \\
\hline Conductivity $\left[\mathrm{mS} \mathrm{cm}^{-1}\right]\left(21.7^{\circ} \mathrm{C}\right)$ & 6.8 \\
Surface tension $\left[\mathrm{mN} \mathrm{m}^{-1}\right]\left(21.6^{\circ} \mathrm{C}\right)$ & $61.7 \pm 0.3$ \\
\hline
\end{tabular}

between needle and collector electrodes is usually $30 \mathrm{kV}$ [56]. The needleless system requires a higher voltage of tens of $\mathrm{kV}$, usually from 30 up to $80 \mathrm{kV}$. The high electric field strength allows more productive electrospinning of some challenging systems with significant surface tension, such as water-based solutions.

Electrospinning is frequently exploited for the preparation of various nanofibrous inorganic compounds [52,58]. While the oxide and other non-metallic materials are commonly prepared by the electrospinning route, the nanofibrous metals are represented only by $\mathrm{Fe}, \mathrm{Co}, \mathrm{Ni}, \mathrm{Pt}$, and $\mathrm{Cu}$ [59]. Platinum [60-64] and copper [65,66] metal nanofibers are well described in multiple morphologies, including their alloys with various metals [63,64]. Iron [67,68], cobalt [67,68], and nickel $[68,69]$ nanofibers are preferentially studied for their magnetic properties. The primary preparation strategy is based on the reduction of corresponding metal oxides in a hydrogen atmosphere. However, in the case of platinum, the oxidation step for removing the supporting polymer and decomposition of the platinum precursor is sufficient to obtain metallic structures in onestep calcination. Despite these successful efforts, the collection of electrospun metallic nanofibers is surprisingly small and lacks important elements, including tungsten.

Here, we report a high-yield method for preparing multigram batches of polycrystalline tungsten nanofibers by needleless electrospinning from aqueous solution silicotungstic acid $\mathrm{H}_{4} \mathrm{SiW}_{12} \mathrm{O}_{40}$ and polyvinyl alcohol followed by a reduction in forming gas.

\section{Experimental procedures}

\subsection{Materials and Methods}

Polyvinyl alcohol (PVA, Mowiol 18-88) and silicotungstic acid hydrate $\mathrm{H}_{4} \mathrm{SiW}_{12} \mathrm{O}_{40}$ (purum) were obtained from Sigma-Aldrich and used as received. Deionized water was used as a solvent. Hydrofluoric acid (48 wt\%, PENTA, Czech Republic) was used for the silica leaching experiment.

For electrospinning, a Nanospider NS LAB500S device (Elmarco, Czech Republic) was used. It is equipped with a cylindrical electrode with micro blades for the allocation of electrical charge and solution droplets.

Prepared solutions were characterized by conductometry, viscosimetry, and surface tension measurements. The electrical 


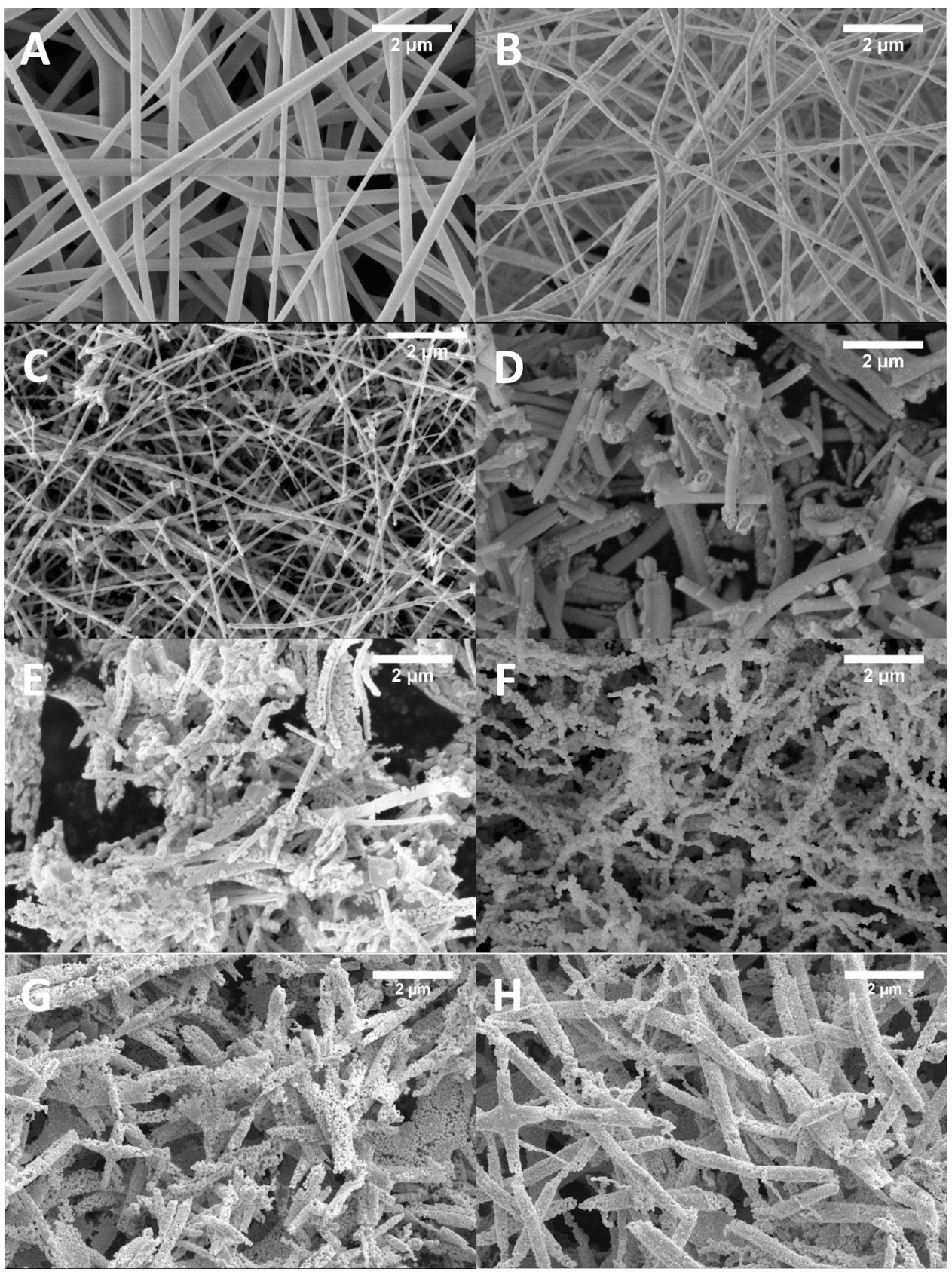

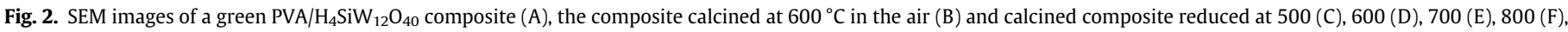
$900(\mathrm{G}), 1000(\mathrm{H}){ }^{\circ} \mathrm{C}$.

conductivity of solutions was obtained on a Cond51 conductometer from XS Instrument. Viscosity measurement was performed on an Alpha Fungilab rotational viscosimeter. Surface tension was obtained by measurement on a Sigma 700 tensiometer equipped with a Wilhelmy probe.

Prepared nanofibrous materials were characterized by scanning electron microscopy (SEM) on a Versa 3D microscope (FEI/Fischer Scientific, Czech Republic). Transmission electron microscopy (TEM) was performed on a FEI Tecnai G2 microscope at $200 \mathrm{kV}$ equipped with a $4 \mathrm{k}$ CCD camera FEI Eagle. The STEM-EDS measurements were performed on a FEI Titan Themis instrument with a combination of a spherical aberration image (Cs) corrector, a monochromator system, sensitive ChemiSTEM technology, and a high-end GATAN GIF Quantum energy filter for EELS and EFTEM with a new enhanced piezo stage, FEI and GATAN software, and an FEI Ceta 16-megapixel CMOS camera. Samples for these analyses were dispersed in methanol, and $4 \mu \mathrm{l}$ of the suspension was placed on a Quantifoil copper grid and allowed to dry by evaporation at ambient temperature. Micrographs were analyzed by the ImageJ software for fiber diameter and size distribution. STEM-EDS figures were processed by the software Velox. The distribution of elements is depicted based on the signal intensity.

Thermogravimetric analysis and differential scanning calorimetry (TG/DSC) was performed on a Netzsch Jupiter STA 449 instrument with a heating rate of $10 \mathrm{~K} \mathrm{~min}^{-1}$ and a maximum temperature of $1000{ }^{\circ} \mathrm{C}$. Measurements in the air were performed with a DSC holder and a Pt/Rh sensor, while measurements in the atmosphere of forming gas were performed with a DTA holder with a W/Re sensor. Reducing atmosphere was purified by deoxygenation cartridge and by a $\mathrm{Zr}$ getter.

The X-ray powder diffraction (XRD) measurements were performed on an Empyrean instrument (PanAnalytical) with a Co $\left(\lambda_{\mathrm{K} \alpha}=\right.$ 

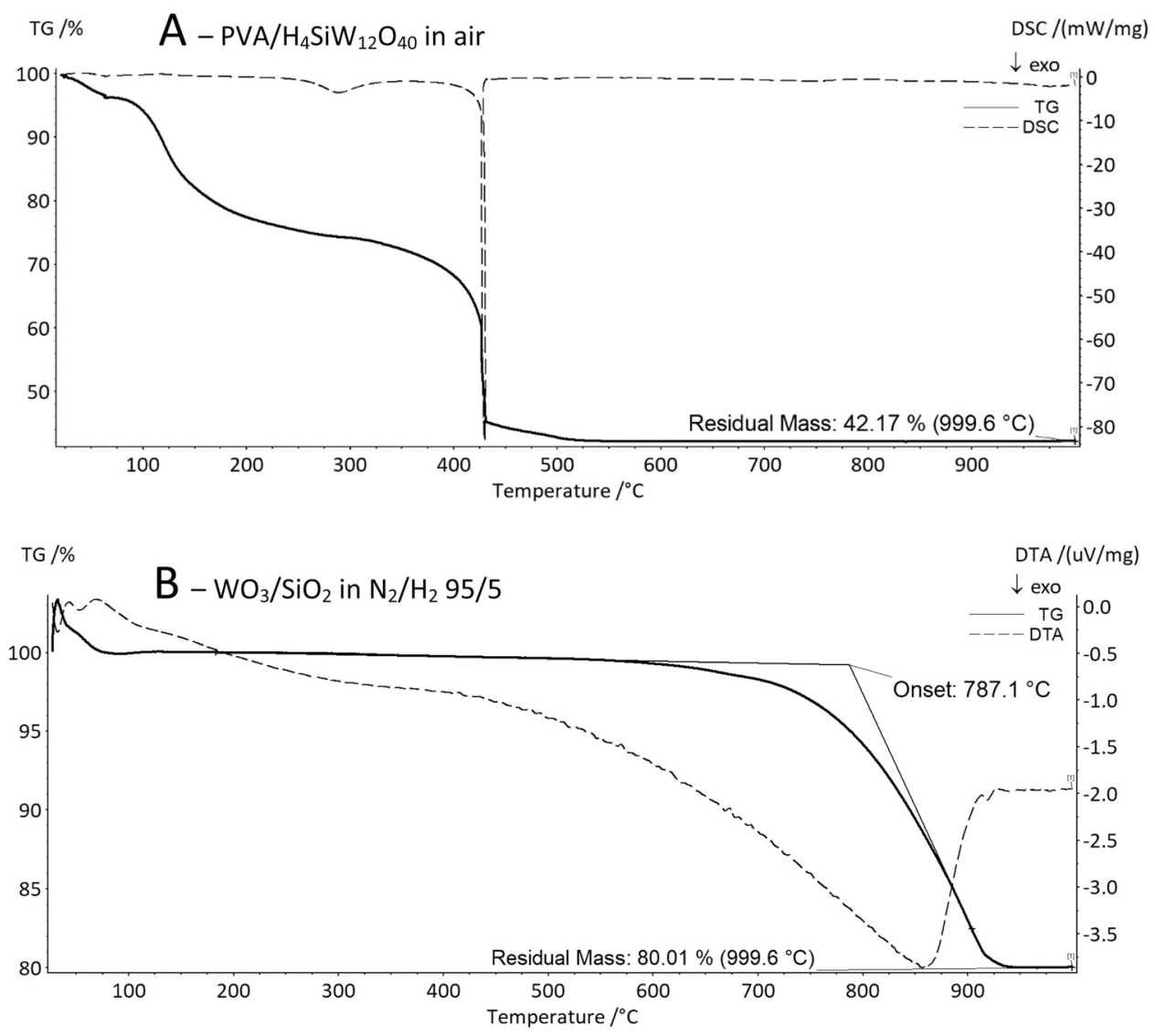

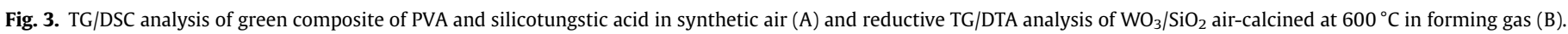

$1.79030 \AA$ ) X-ray lamp at room temperature. The Rietveld computation determined the phase composition with the evaluation of crystalline size using the Scherrer equation by HighScorePlus 4.0 (PanAnalytical) equipped with a model from the ICSD database.

The samples for elemental analysis were dissolved in aqueous solutions of $\mathrm{KOH}$ and $\mathrm{H}_{2} \mathrm{O}_{2}$. A typical procedure involved precise sample weighing (e.g., $0.0300 \mathrm{~g}$ ) directly into a fluoropolymer digestion vessel (Savillex) and the addition of $1 \mathrm{~cm}^{3}$ of $30 \% \mathrm{KOH}$ solution. The resulting suspension was ultrasonically treated for $2 \mathrm{~min}$ and heated at $150{ }^{\circ} \mathrm{C}$ for $1 \mathrm{~h}$. Aqueous $\mathrm{H}_{2} \mathrm{O}_{2}$ was added $\left(0.2 \mathrm{~cm}^{3}\right)$ after cooling down, and samples were repeatedly heated. When complete dissolution was not achieved, additional $\mathrm{H}_{2} \mathrm{O}_{2}$ was added $\left(0.1 \mathrm{~cm}^{3}\right)$ and heated till complete dissolution. After cooling down, the content of the reactor was quantitatively transferred to an analytical flask and filled with deionized water. The prepared solution was analyzed by the inductively coupled plasma method (ICP-OES) using an iCAP 6500 Duo spectrometer (Thermo, generator $27.12 \mathrm{MHz}$, amplitude $1.15 \mathrm{~kW}$, plasma gas flow $12 \mathrm{dm}^{3} \mathrm{~min}^{-1}$ ), emission lines 224.9 and $207.9 \mathrm{~nm}$ for $\mathrm{W}$ and 212.4 and $221.6 \mathrm{~nm}$ for $\mathrm{Si}$.

\subsection{Preparation of electrospinning solution and its characterization}

PVA (150.0 g) was dissolved in deionized water (1150.0 g) by stirring and heating for several hours. Silicotungstic acid hydrate (120.0 g) was separately dissolved in deionized water (200.0 g). After cooling down to an ambient temperature, both prepared solutions were mixed and homogenized by intensive stirring for several hours. A clear, colorless viscous solution was formed. Its properties are described in Table 1.

\subsection{Needleless electrospinning}

The prepared solution (approx. $800 \mathrm{~cm}^{3}$ ) was transferred to the electrode vessel with a partially submerged electrode. The grounded counter electrode in the form of stretched wire was covered with a large sheet of aluminum foil (approx. $0.8 \times 0.4 \mathrm{~m}$ ), and the distance was set to $20 \mathrm{~cm}$. The speed of electrode rotation was set to $30 \mathrm{rpm}$. The applied voltage was set to $70 \mathrm{kV}$. The process has been running for approximately $4 \mathrm{~h}$ when half of the used solution was depleted, and the aluminum collector was covered by a thick layer of nonwoven felt of a green composite of PVA and silicotungstic acid. The prepared material was peeled off, analyzed by SEM and TG/DSC to obtain suitable calcination temperature, and used in further processing.

\subsection{Calcination and high-temperature treatment}

Collected layers of electrospun fibers were treated in a muffle furnace with the heating rate set to $4 \mathrm{~h}$ to reach the maximum temperature of $600{ }^{\circ} \mathrm{C}$, which was maintained for additional $4 \mathrm{~h}$. The calcination process was finished by spontaneous cool down to ambient temperature. After this treatment, materials were collected and analyzed by the SEM, TEM, and XRD methods. TG/DTA measurements in a reduction atmosphere of forming gas have been performed to obtain the onset temperature of the reduction process.

Calcination was followed by reduction treatment in forming gas in a tube furnace set at various temperatures $\left(500-1000{ }^{\circ} \mathrm{C}\right)$. The heating program consisted of a ramp $(4 \mathrm{~h})$ to reach the maximum temperature and of dwell time $(4 \mathrm{~h})$ followed by spontaneous cooling down to an ambient temperature. A flow of forming gas was 


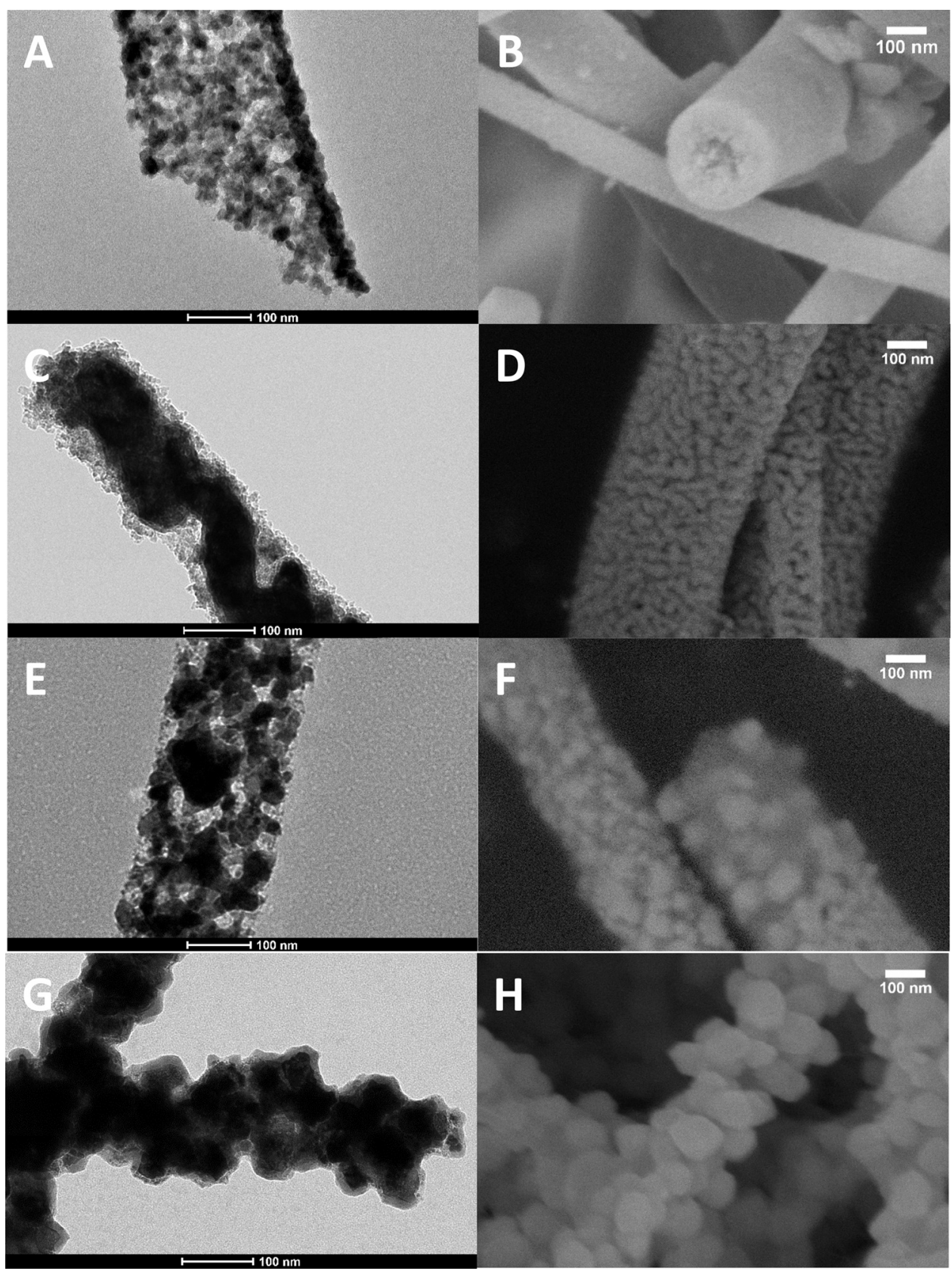

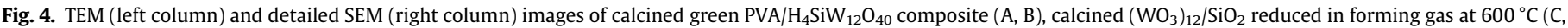
D), $700{ }^{\circ} \mathrm{C}(\mathrm{E}, \mathrm{F})$, and $800^{\circ} \mathrm{C}(\mathrm{G}, \mathrm{H})$. Samples prepared at 900 and $1000^{\circ} \mathrm{C}$ are shown separately in Fig. $6 \mathrm{~S}$ (SEM), $7 \mathrm{~S}$, and $8 \mathrm{~S}(\mathrm{STEM}-\mathrm{EDS})$.

supplied from the gas cylinder in the composition of $5 / 95 \mathrm{H}_{2}$ in $\mathrm{N}_{2}$. The prepared materials were collected and characterized by elemental analysis and by the SEM, TEM, and XRD methods.

Leaching of formed silica was performed by applying an excess of hydrofluoric acid and leaving the plastic vial overnight at an ambient temperature $\left(23^{\circ} \mathrm{C}\right)$ without stirring. After leaching, HF was decanted, the sample was gently covered by an excess of deionized water and decanted several times; this was followed by the final addition of acetone, decantation, and drying in air. After the process, the sample was analyzed by the SEM and STEM-EDS techniques.

\section{Results and discussion}

Investigation of the synthesis process of polycrystalline tungsten nanofibers started with the selection of tungsten-containing, watersoluble precursors. The silicotungstic acid $\mathrm{H}_{4} \mathrm{SiW}_{12} \mathrm{O}_{40}$ was used because of its excellent water solubility and compatibility with polyvinyl alcohol, which is crucial for preparing stable and electrospinnable aqueous solutions [70]. Silicon content in the final material form introduces another morphology-controlling factor, i.e., the possibility of post-synthetic leaching of amorphous $\mathrm{SiO}_{2}$ from intergrain spaces.

Initially, the prepared precursor solution was tested for its electrospinnability on a lab-scale needle electrospinning device; however, spinnability from an aqueous mixture was very time demanding due to a low evaporation rate and dripping of the solution. Therefore, the feed rate of the process had to be set to several microliters per minute while the electric field strength was $1 \mathrm{kV} \mathrm{cm}^{-1}$ with $15 \mathrm{~cm}$ electrode distance. In contrast, employing a needleless electrospinning system is beneficial due to a much larger surface area of the electrode and the collector. The Nanospider device can sustain a much stronger electric field of $70 \mathrm{kV}$ on a positive 


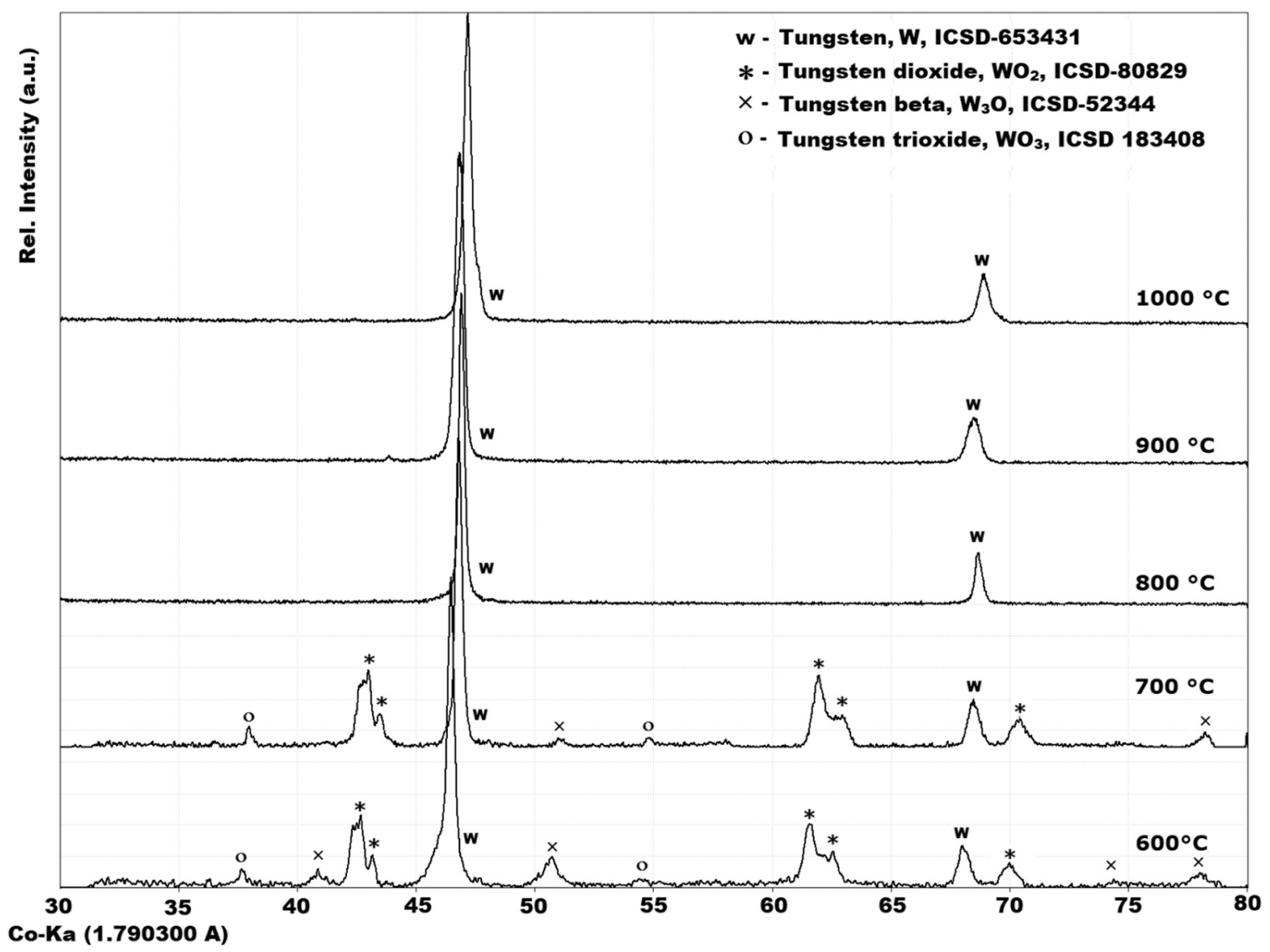

Fig. 5. XRD diffractograms of materials obtained by the reduction reactions of $\left(\mathrm{WO}_{3}\right)_{12} / \mathrm{SiO}_{2}$ in forming gas at different temperatures $\left(600,700,800,900,1000{ }^{\circ} \mathrm{C}\right)$.

electrode, submerged into the solution, and a distance of $20 \mathrm{~cm}$, resulting in the electric field strength of $3.5 \mathrm{kV} \mathrm{cm}^{-1}$. The electrospinning process occurred from approximately $2.0 \mathrm{kV} \mathrm{cm}^{-1}$; however, the fiberforming process appeared more productive when we applied a stronger electrical field. The addition of PVA polymer and silicotungstic acid lowered the surface tension from the value of pure water; however, it remained substantially high compared to organic solvents, which are more suitable for higher production rates even from the laboratory needle-based electrospinning devices.

On the other hand, aqueous systems are better applicable in the open vessels of needleless electrospinning. Organic solvents evaporate too quickly from the open solution surface, and a polymer with an inorganic precursor precipitate before electrode transport could happen. After the electrospinning process, the light green paper-like mat was collected and analyzed by the SEM (Fig. 2A) and TG/DSC (Fig. 3A) methods.

The SEM analysis of electrospun green PVA $/ \mathrm{H}_{4} \mathrm{SiW}_{12} \mathrm{O}_{40}$ composite revealed smooth, round polymer-based fibers with an average diameter of $355 \pm 181 \mathrm{~nm}$ and relatively broad diameter distribution, which is described in the histogram (Fig. 1S) in the Supplementary Information.

Thermogravimetric analysis (Fig. 3A) was used to determine the effective calcination temperature to obtain purely inorganic material without organic polymer residues. By increasing the temperature, the mass loss occurs up to approximately $400^{\circ} \mathrm{C}$, which is followed by the exothermic burnout at $427^{\circ} \mathrm{C}$. Above $550{ }^{\circ} \mathrm{C}$, the residual mass remains constant at $42.2 \%$, which corresponds with the chemical composition of the starting material, polymer oxidation, and loss of water. Thus, the calcination temperature was set to $600{ }^{\circ} \mathrm{C}$ based on the obtained TG/DSC results.
The subsequent calcination process was performed in an alumina crucible in a muffle furnace at $600{ }^{\circ} \mathrm{C}$. It resulted in a yellow flakelike brittle material, which was analyzed by SEM (Figs. 2B, 4B), TEM (Fig. 4A), and reductive TG/DTA in forming gas (Fig. 3B). The result of XRD measurement is shown in the Supplementary Information (Fig. 2S), and observed diffractions correspond to the monoclinic $\mathrm{WO}_{3}$ phase (ICSD-183408). The SEM analysis (Fig. 2B) of calcined fibers has shown an expected decrease of the average diameter of fibers to $153 \pm 43 \mathrm{~nm}$. Morphology of fibers changed from smooth organic fibers to inorganic polycrystalline structures with a rough surface. Closer observation by TEM showed inner crystallinity (Fig. 4A), and the partial hollow character of some fibers appeared in the detailed SEM images (Fig. 4B). The histogram describing the distribution of fibers thickness is attached in Supplementary Information (Fig. 1S). Collected calcined fibers were mineralized and subjected to the elemental analysis by ICP-OES, which provided tungsten and silicon contents of $74.9 \pm 0.1 \%$ and $0.973 \pm 0.010 \%$, respectively. These values relatively closely correspond to the theoretical content of $76.98 \%$ and $0.988 \%$ for the $\left(\mathrm{WO}_{3}\right)_{12} / \mathrm{SiO}_{2}$ stoichiometry.

TG/DTA measurement was performed on calcined material in forming gas $\mathrm{N}_{2} / \mathrm{H}_{2} 95 / 5$ (Fig. 3B) to investigate the reduction process of $\mathrm{WO}_{3} / \mathrm{SiO}_{2}$ to lower tungsten oxides and to metallic tungsten [71]. The goal of the analysis was to determine the proper temperature for the complete reduction. The process onset was calculated at $787^{\circ} \mathrm{C}$, while the final residual mass was reached at a relatively high temperature of approximately $950{ }^{\circ} \mathrm{C}$. The residual mass remained at $80.0 \%$ of the original weight, which closely corresponds to the theoretical value (79.6\%) for a complete reduction of $\left(\mathrm{WO}_{3}\right)_{12} / \mathrm{SiO}_{2}$ to metallic $\mathrm{W}$ and a stoichiometric amount of $\mathrm{SiO}_{2}$. 

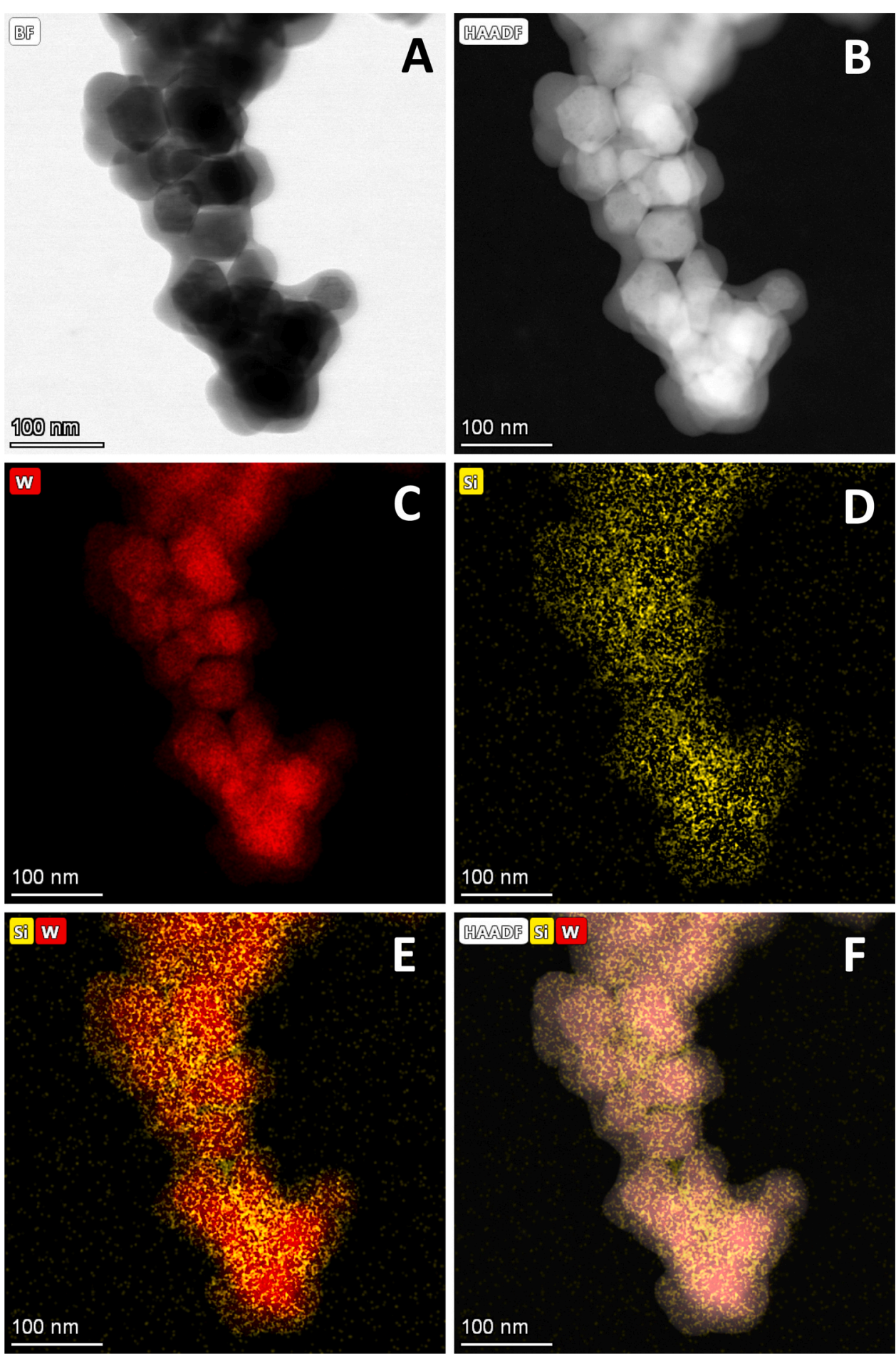

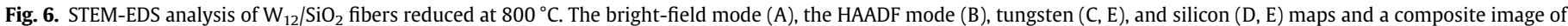
$\mathrm{W}$ and $\mathrm{Si}$ elemental composition and $\operatorname{HAADF}(\mathrm{F})$.

Six temperatures were selected for reduction treatment (500, $600,700,800,900$, and $1000^{\circ} \mathrm{C}$ ) based on the TG/DTA analysis. The reduction reactions were performed in a tube furnace in a flow of forming gas. The products were collected after cooling down and analyzed by SEM (Figs. 2C-H, 4D, 4F, 4H, 6S), TEM (Fig. 4C, E, G), STEM-EDS (Fig. 6, 7S, 8S), and XRD (Figs. 5, 3S).

The SEM measurements (Fig. 2C) and the XRD analysis (Fig. 3S) of reduction products show morphological and phase changes in the system. The reaction at $500^{\circ} \mathrm{C}$ produced a distinctive blue brittle material, which was identified as a mixture of reduced tungsten blue oxide $\mathrm{WO}_{2.90}$ (ISCD-24736) and $\mathrm{WO}_{3}$ (ICSD-183408) in a 66:34 ratio (Fig. 3S). The particle size obtained from the Scherrer equation was $20 \mathrm{~nm}$ for the $\mathrm{WO}_{2.90}$ phase. Morphology of the material remains fibrous with an average diameter of $147 \pm 47 \mathrm{~nm}$. The histogram of fiber thickness is attached in the Supplementary Information (Fig. 1S). The elemental analysis provided tungsten and silicon contents of $77.2 \pm 0.2 \%$ and $1.042 \pm 0.006 \%$, respectively, corresponding with the observed partial reduction to lower tungsten oxide.

The reduction treatment at $600{ }^{\circ} \mathrm{C}$ produces a black powder with a structure different from the previous sample. Thinner fibers 


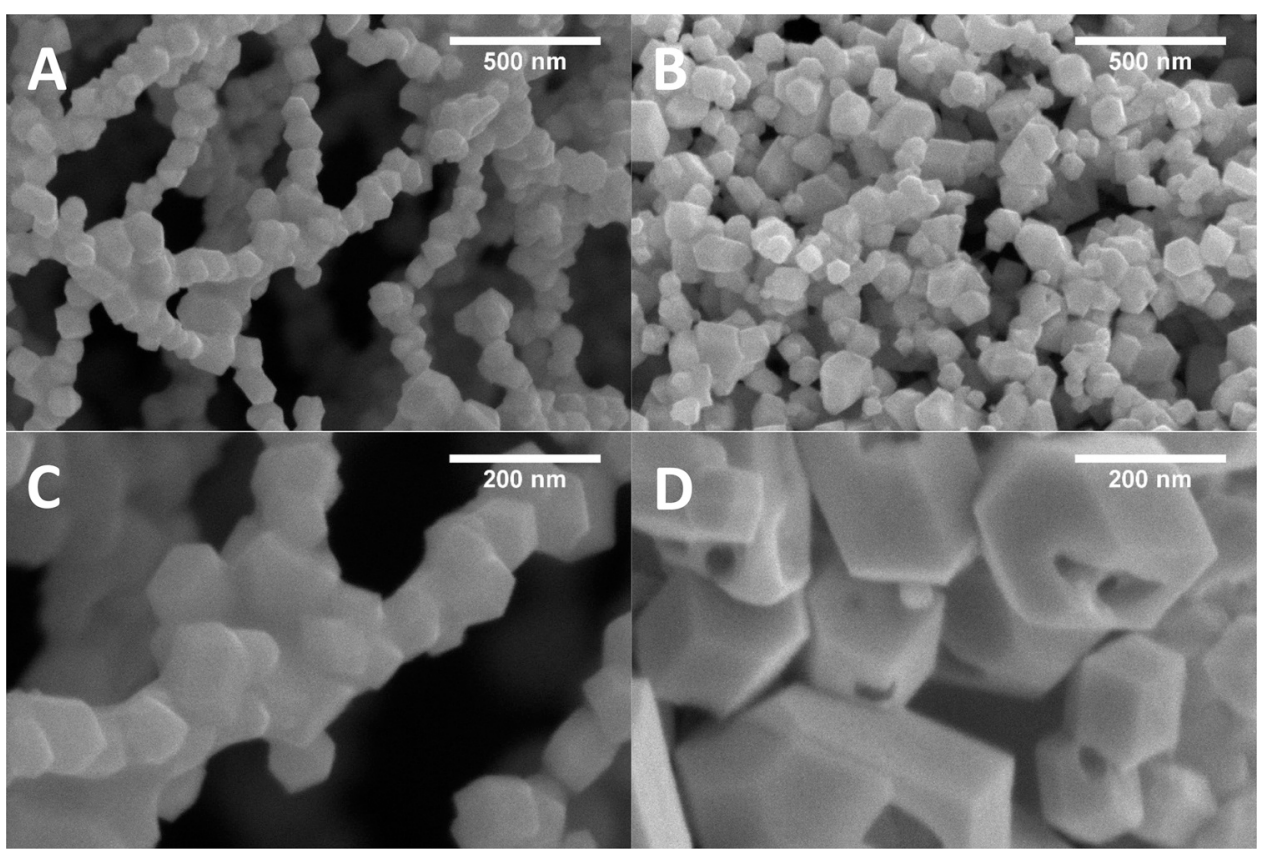

Fig. 7. $\mathrm{SEM}$ analysis and comparison of the $\mathrm{W} / \mathrm{SiO}_{2}$ composite reduced at $800^{\circ} \mathrm{C}(\mathrm{A}, \mathrm{C})$ and its $\mathrm{HF}$ leached counterpart (B, D).
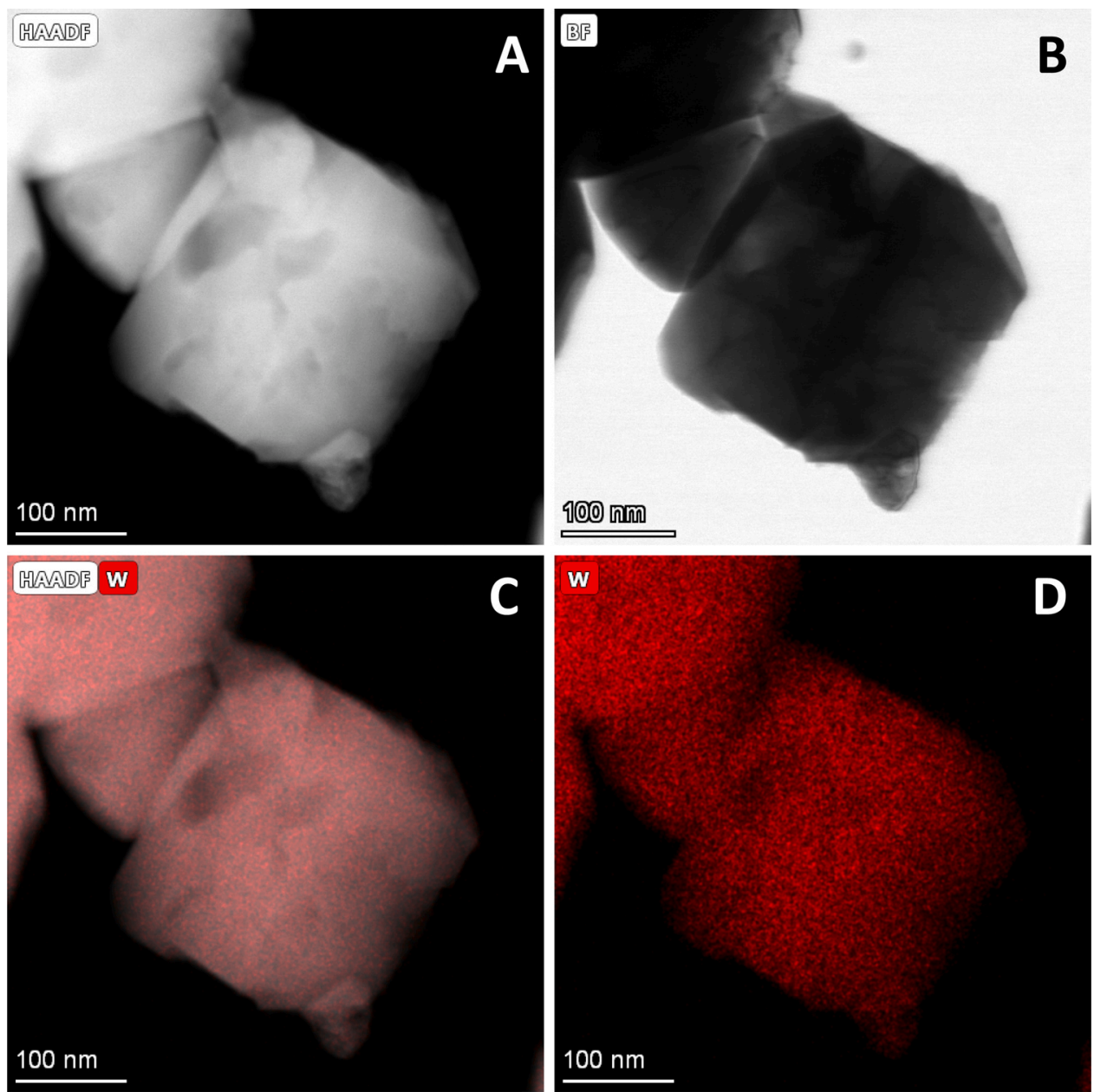

Fig. 8. STEM-EDS analysis of the HF-leached sample of a $\mathrm{W} / \mathrm{SiO}_{2}$ composite reduced at $800^{\circ} \mathrm{C}$. The HAADF mode (A), the bright field mode (B), EDS mapping of tungsten together with HAADF image (C), and EDS mapping of tungsten (D). 
Table 2

Results of $\mathrm{W}$ and $\mathrm{Si}$ elemental analyses of the $\left(\mathrm{WO}_{3}\right)_{12} / \mathrm{SiO}_{2}$ composites reduced in forming gas at different temperatures.

\begin{tabular}{lll}
\hline $\begin{array}{l}\text { Reduction temp. } \\
{\left[{ }^{\circ} \mathrm{C}\right]}\end{array}$ & $\begin{array}{l}\text { W content } \\
{[\%]}\end{array}$ & $\begin{array}{l}\text { Si content }[\%] \\
( \pm 0.01 \%)\end{array}$ \\
\hline$\left(\mathrm{WO}_{3}\right)_{12} / \mathrm{SiO}_{2}$ (theor.) & 76.98 & 0.99 \\
$\left(\mathrm{WO}_{3}\right)_{12} / \mathrm{SiO}_{2}$ (exp.) & $74.9 \pm 0.1$ & 0.97 \\
500 & $77.2 \pm 0.2$ & 1.04 \\
600 & $81.7 \pm 0.2$ & 1.10 \\
700 & $88.5 \pm 0.3$ & 1.22 \\
800 & $93.7 \pm 0.3$ & 1.28 \\
900 & $93.6 \pm 0.9$ & 1.22 \\
1000 & $93.6 \pm 0.5$ & 1.26 \\
$\mathrm{~W}_{12} / \mathrm{SiO}_{2}$ (theor.) & 97.35 & 1.24 \\
\hline
\end{tabular}

collapsed, and thicker ones have been transformed to open porous structures (Fig. 4D). The TEM measurement (Fig. 4C) revealed the formation of particles identified as metallic $\mathrm{W}$ by the XRD analysis (Fig. 5). However, the reduction was not completed at applied temperature, and the sample contained three other phases next to $\alpha-\mathrm{W}$ (36\%, ICSD-653431). Residual, still unreduced, $\mathrm{WO}_{3}$ minor phase $(1 \%$, ICSD-183408), $\mathrm{WO}_{2}$ (39\%, ICSD-80829), and $\mathrm{W}_{3} \mathrm{O}$ (24\%, ICSD-52344) were also present. The calculated particle size from the Scherrer equation was $28 \mathrm{~nm}$ for metallic tungsten. Elemental analysis of mineralized fibers provided tungsten and silicon content of $81.7 \pm 0.2 \%$ and $1.103 \pm 0.008 \%$, respectively. An increase of tungsten content shows a partial reduction process during the treatment.

A higher reduction temperature of $700{ }^{\circ} \mathrm{C}$ caused further growth of metallic cores (Fig. 4E), but porous morphology, as in the previous case, was not observed as a dominant structural motif (Fig. 2E). Detailed analysis by TEM (Fig. 4E) corresponds with a higher magnification image obtained by SEM (Fig. 4F), which shows the enlargement of tungsten particles; however, the size distribution was challenging to establish due to uncertain boundaries between individual particles. The XRD analysis revealed phase composition similar to the previous sample with the traces of $\mathrm{W}_{3} \mathrm{O}(1 \%)$ and different content of other phases, which were $\mathrm{WO}_{2}$ (51\%), $\alpha-\mathrm{W}(45 \%)$, and residual $\mathrm{WO}_{3}(3 \%)$. The ICP-OES analysis revealed tungsten content to $88.5 \pm 0.3 \%$. Silicon content of $1.22 \pm 0.01 \%$ was measured. Results follow the trend of increasing tungsten content while preserving the tungsten-silicon ratio.

At a reduction temperature of $800^{\circ} \mathrm{C}$, the sample was converted to pure polycrystalline tungsten (Fig. 5) with incorporated amorphous silica. Morphology has changed to relatively large, connected grains forming dense polycrystalline fibers (Figs. 2F, 4G, 4H). The average diameter of fibers was not measured due to the high level of shape irregularities. Therefore, the average grain diameter was determined instead and compared to the grain size of the sample reduced at $600{ }^{\circ} \mathrm{C}$ based on its TEM measurement. While reduction at $600{ }^{\circ} \mathrm{C}$ formed grains with a size of $64 \pm 29 \mathrm{~nm}$, reduction at $800^{\circ} \mathrm{C}$ produced the average grain size of $107 \pm 49 \mathrm{~nm}$. Distributions of obtained grain sizes are attached in the Supplementary Information (Fig. 4S). The measurement was taken only from distinct dark particles observable in the TEM images. The XRD analysis (Fig. 5) proved that the only crystalline phase present was $\alpha-W$ (ICSD-653431). The Scherrer equation provided a crystallite size of $48 \mathrm{~nm}$, lower than the observed diameter of individual grains. The elemental analysis of mineralized fibers provided $\mathrm{W}$ and $\mathrm{Si}$ content of $93.7 \pm 0.3 \%$ and $1.28 \pm 0.01 \%$, respectively. The results show an almost complete reduction to elemental tungsten (theoretically $97.35 \% \mathrm{~W}$ for $\mathrm{W}_{12} /$ $\mathrm{SiO}_{2}$ ) and a relatively constant tungsten-to-silicon ratio. The sample was analyzed by the STEM-EDS technique (Fig. 6) to observe elemental distribution in the prepared material.

The STEM-EDS analysis provided insight into the inner structure of the fibers composed of separated tungsten nanoparticles (Fig. 6C) covered with amorphous silica film (Fig. 6D). An EDS profile crosssection diagram (Fig. 5SA) shows a stronger silicon signal at the edges of the fiber (Fig. 5SB). That corresponds with the TEM analysis in a bright field mode (Fig. 6A), showing tungsten grains covered with amorphous silica on the surface and between individual tungsten grains. Therefore, we assume that silica acts as a binder for tungsten particles, helps form polycrystalline nanofibers, and stabilizes the fibrous morphology at high temperatures. We have performed leaching with hydrofluoric acid followed by the SEM (Fig. 7) and STEM-EDS (Fig. 8) analyses to prove that assumption.

Macroscopically no profound change in the morphology of the black powder after the HF treatment was observed; however, the SEM analysis showed significant changes in the morphology. While in an untreated sample, the tungsten grains are covered with amorphous material (Fig. 7A, C), in the treated material fibrous structure with interlinked tungsten grains bonded together by amorphous silica collapsed (Fig. 7B). Individual grains are revealed with etched surfaces and clearly visible holes (Fig. 7D).

The leached material was subjected to the STEM-EDS analysis. A selected HF-treated particle was analyzed to see both the etched surface and holes in the grain. In the HAADF and bright-field mode measurements (Fig. 8A, B), the apparent shapes of leached tungsten particles are observed without the silica shell. The images could be compared with an untreated sample (Fig. 6A, B) where silica is still intact. The HAADF analysis (Fig. 8A) and EDS mapping (Fig. 8C, D) proved that only tungsten was present in the sample. Based on these observations, we surmise that polycrystalline tungsten nanofibers are formed mainly by amorphous silica holding $\mathrm{W}$ particles in the fibrous morphology of this composite material. The force present between tungsten particles and silica is adhesive in nature. This particulate structure corresponds with the notoriously poor sintering properties of tungsten.

Materials prepared at 900 and $1000^{\circ} \mathrm{C}$ (Fig. 2G, H, respectively) showed a slightly different morphology where individual interconnected nanoparticles have collapsed into much thicker submicron fibers. However, the prepared samples were not homogenous, and partially bulk structures were observed in both cases (Fig. 6SA, B). Both samples were analyzed by STEM-EDS to observe sintered structures (Figs. 7S, 8S). Finally, both samples were mineralized and analyzed for their elemental composition. The tungsten-based material resulting from the reaction at $900{ }^{\circ} \mathrm{C}$ consisted of almost the same percentage of tungsten as the sample prepared at $800{ }^{\circ} \mathrm{C}(93.6 \pm 0.5 \%)$. The silicon content of $1.22 \pm 0.01 \%$ was also similar to the previous case. The highest reduction temperature of $1000{ }^{\circ} \mathrm{C}$ provided material with comparable tungsten and silicon contents of $93.6 \pm 0.5 \%$ and $1.26 \pm 0.01 \%$, respectively. The results from the elemental analysis of prepared materials are summarized in Table 2.

For increasing reduction temperatures from $500^{\circ}$ to $800^{\circ} \mathrm{C}$, we can observe a steady increase of tungsten and silicon contents, corresponding with the chemical process and lowering the oxygen proportion. Higher temperatures of 900 and $1000{ }^{\circ} \mathrm{C}$ are not beneficial to further reduction. Therefore, we can state that a temperature of $800{ }^{\circ} \mathrm{C}$ is the most suitable to retain the nanofibrous and nanoscopic character of the sample, which disappears during sintering at more elevated temperatures.

\section{Conclusions}

For the first time, we report the preparation of polycrystalline tungsten fibers with diameters in nanoscopic and submicron range by needleless electrospinning. We have selected silicotungstic acid as a tungsten source due to the presence of a silica-forming agent incorporated in the structure as a possible source of defects or leachable structural elements during future work-up towards catalytically active materials. Another reason for the selection is the excellent water solubility of this precursor and its compatibility with polyvinyl alcohol. The water-based solution was successfully 
electrospun on the Nanospider electrospinning device from the free surface electrode providing a good multigram yield of green fibers composed of PVA and silicotungstic acid. Based on the thermogravimetric analysis, a proper calcination temperature of $600{ }^{\circ} \mathrm{C}$ was found, leading to a purely inorganic material, which was identified as a $\left(\mathrm{WO}_{3}\right)_{12} / \mathrm{SiO}_{2}$ composite in the form of submicron fibers. The material was again analyzed by thermogravimetry; however, now in the reducing atmosphere of forming gas. Based on these results, six different temperatures for the reduction treatment were tested, and the obtained materials were characterized. Partially reduced samples were obtained from $500^{\circ}$ to $700^{\circ} \mathrm{C}$, while at $800^{\circ} \mathrm{C}$, desired polycrystalline metallic fibers composed of tungsten nanograins with an average diameter of $107 \pm 49 \mathrm{~nm}$ were acquired. Employing the STEM-EDS and SEM analyses, we have found that the individual tungsten grains form nanofibers with the help of amorphous silica covering and connecting metallic nanoparticles. The obtained materials have enlarged the family of tungsten nanoscopic materials and could be further used in fabrication of catalytically active systems, such as tungsten chalcogenides [72], carbides [73], Pt/W, Ni/W alloys, and other modified tungsten-based systems [16]. The incorporation of $\mathrm{W}$ nanofibers into a polymer matrix could yield composites suitable as X-ray shielding materials [74]. The presented simple electrospinning technique could decrease the cost of the fabrication process and overcome the main limitations that hamper the commercial implementation of tungsten nanowires.

\section{CRediT authorship contribution statement}

Vojtech Kundrat - performed all syntheses experiments and some characterization measurements, wrote the first draft of the manuscript, Vit Vykoukal - performed characterization by electron microscopy, prepared figures, and proofread the manuscript, Zdenek Moravec - performed thermal analysis measurements, analyzed data, and proofread the manuscript, Lucie Simonikova - performed analytical measurements and proofread the manuscript, Karel Novotny - analyzed the characterization data and proofread the manuscript, Jiri Pinkas - designed the syntheses and characterization experiments, wrote the advanced versions of the manuscript, coordinated the work.

\section{Declaration of Competing Interest}

The authors declare that they have no known competing financial interests or personal relationships that could have appeared to influence the work reported in this paper.

\section{Acknowledgments}

We acknowledge Cryo-Electron Microscopy and Tomography Core Facility of CIISB, Instruct-CZ Centre, supported by MEYS, Czech Republic (LM2018127). CzechNanoLab project LM2018110 funded by MEYS, Czech Republic is gratefully acknowledged for the financial support of the measurements/sample fabrication at CEITEC Nano Research Infrastructure. This research has been financially supported by the Horizon 2020 Research and Innovation Program, European Union under grant agreement no. 810626 (SINNCE).

\section{Appendix A. Supporting information}

Supplementary data associated with this article can be found in the online version at doi:10.1016/j.jallcom.2021.163542.

\section{References}

[1] D. Huo, M.J. Kim, Z. Lyu, Y. Shi, B.J. Wiley, Y. Xia, One-dimensional metal nanostructures: from colloidal syntheses to applications, Chem. Rev. 119 (2019) 8972-9073, https://doi.org/10.1021/acs.chemrev.8b00745

[2] T. Sannicolo, M. Lagrange, A. Cabos, C. Celle, J.-P. Simonato, D. Bellet, Metallic nanowire-based transparent electrodes for next generation flexible devices: a review, Small 12 (2016) 6052-6075, https://doi.org/10.1002/smll.201602581

[3] J. Ahn, H. Hwang, S. Jeong, J. Moon, Metal-nanowire-electrode-based perovskite solar cells: challenging issues and new opportunities, Adv. Energy Mater. 7 (2017) 1602751, https://doi.org/10.1002/aenm.201602751

[4] J. Liu, D. Jia, J.M. Gardner, E.M.J. Johansson, X. Zhang, Metal nanowire networks: recent advances and challenges for new generation photovoltaics, Mater. Today Energy 13 (2019) 152-185, https://doi.org/10.1016/j.mtener.2019.05.007

[5] S.A. Hashemi, S. Ramakrishna, A.G. Aberle, Recent progress in flexible-wearable solar cells for self-powered electronic devices, Energy Environ. Sci. 12 (2020) 685-743, https://doi.org/10.1039/c9ee03046h

[6] A. Kamyshny, S. Magdassi, Conductive nanomaterials for 2D and 3D printed flexible electronics, Chem. Soc. Rev. 48 (2019) 1712-1740, https://doi.org/10. 1039/c8cs00738a

[7] G. Chen, Y. Li, M. Bick, J. Chen, Smart textiles for electricity generation, Chem. Rev. 120 (2020) 3668-3720, https://doi.org/10.1021/acs.chemrev.9b00821

[8] X. Peng, K. Dong, C. Ye, Y. Jiang, S. Zhai, R. Cheng, D. Liu, X. Gao, J. Wang, Z.L. Wang, A breathable, biodegradable, antibacterial, and self-powered electronic skin based on all-nanofiber triboelectric nanogenerators, Sci. Adv. 6 (2020) eaba9624, https://doi.org/10.1126/sciadv.aba9624

[9] R. Yin, S. Yang, O. Li, S. Zhang, H. Liu, J. Han, C. Liu, C. Shen, Flexible conductive Ag nanowire/cellulose nanofibril hybrid nanopaper for strain and temperature sensing applications, Sci. Bull. 65 (2020) 899-908, https://doi.org/10.1016/j.scib. 2020.02.020

[10] Y. Wei, S. Chen, Y. Lin, X. Yuan, L. Liu, Silver nanowires coated on cotton for flexible pressure sensors, J. Mater. Chem. C. 4 (2016) 935-943, https://doi.org/10. 1039/c5tc03419a

[11] S.M. Mirvakili, I.W. Hunter, Artificial muscles: mechanisms, applications, and challenges, Adv. Mater. 30 (2017) 1704407, https://doi.org/10.1002/adma. 201704407

[12] M. Yao, B. Wang, B. Sun, L. Luo, Y. Chen, J. Wang, N. Wang, S. Komarneni, X. Niu, W. Hu, Rational design of self-supported Cu@WC core-shell mesoporous nanowires for pH-universal hydrogen evolution reaction, Appl. Catal. B: Environ. 280 (2021) 119451, https://doi.org/10.1016/j.apcatb.2020.119451

[13] T. Wasiak, D. Janas, Nanowires as a versatile catalytic platform for facilitating chemical transformations, J. Alloy. Comp. 892 (2021) 162158, https://doi.org/10. 1016/j.jallcom.2021.162158

[14] H. Xu, H. Shang, C. Wang, Y. Du, Ultrafine Pt-based nanowires for advanced catalysis, Adv. Funct. Mater. 30 (2020) 2000793, https://doi.org/10.1002/adfm. 202000793

[15] D. Voiry, H.S. Shin, K.P. Loh, M. Chhowalla, Low-dimensional catalysts for hydrogen evolution and $\mathrm{CO}_{2}$ reduction, Nat. Rev. Chem. 2 (2018) 0105, https://doi. org/10.1038/s41570-017-0105

[16] Q. Li, C. Han, X. Ma, D. Wang, Z. Xing, X. Yang, Bromine and nitrogen co-doped tungsten nanoarrays to enable hydrogen evolution at all $\mathrm{pH}$ values, J. Mater. Chem. A 5 (2017) 17856-17861, https://doi.org/10.1039/c7ta05188c

[17] L. Mai, X. Tian, X. Xu, L. Chang, L. Xu, Nanowire electrodes for electrochemical energy storage devices, Chem. Rev. 114 (2014) 11828-11862, https://doi.org/10. 1021/cr500177a

[18] G. Zhou, L. Xu, G. Hu, L. Mai, Y. Cui, Nanowires for electrochemical energy storage, Chem. Rev. 119 (119) (2019) 11042-11109, https://doi.org/10.1021/acs. chemrev.9b00326

[19] C. Ren, Z.Z. Fang, M. Koopman, B. Butler, J. Paramore, S. Middlemas, Methods for improving ductility of tungsten - a review, Int. J. Refract. Met. Hard Mater. 75 (2018) 170-183, https://doi.org/10.1016/j.ijrmhm.2018.04.012

[20] J. Das, G. Appa Rao, S.K. Pabi, Microstructure and mechanical properties of tungsten heavy alloys, Mater. Sci. Eng. A 527 (2010) 7841-7847, https://doi.org/ 10.1016/j.msea.2010.08.071

[21] E. Lassner, W.-D. Schubert, Tungsten: Properties, Chemistry, Technology of the Element, Alloys, and Chemical Compounds, Kluwer Academic/Plenum Publishers, New York, 1999.

[22] C.-M. Wu, S. Naseem, M.-H. Chou, J.-H. Wang, Y.-Q. Jian, Recent advances in tungsten-oxide-based materials and their applications, Front. Mater. 6 (2019) 49, https://doi.org/10.3389/fmats.2019.00049

[23] H. Zheng, J.Z. Ou, M.S. Strano, R.B. Kaner, A. Mitchell, K. Kalantar-zadeh, Nanostructured tungsten oxide - properties, synthesis, and applications, Adv. Funct. Mater. 21 (2011) 2175-2196, https://doi.org/10.1002/adfm.201002477

[24] Z.Z. Fang, X. Wang, T. Ryu, K.S. Hwang, H.Y. Sohn, Synthesis, sintering, and mechanical properties of nanocrystalline cemented tungsten carbide - a review, Int. J. Refract. Met. Hard Mater. 27 (2009) 288-299, https://doi.org/10.1016/j. ijrmhm.2008.07.011

[25] A. Eftekhari, Tungsten dichalcogenides $\left(\mathrm{WS}_{2}, \mathrm{WSe}_{2}\right.$, and $\left.\mathrm{WTe}_{2}\right)$ : materials chemistry and applications, J. Mater. Chem. A 5 (2017) 18299-18325, https://doi. org/10.1039/C7TA04268J

[26] M. Mohl, A. Rautio, G.A. Asres, M. Wasala, P.D. Patil, S. Talapatra, K. Kordas, 2D tungsten chalcogenides: synthesis, properties and applications, Adv. Mater. Interfaces 7 (2020) 2000002, https://doi.org/10.1002/admi.202000002 
[27] R. Malewar, K.S. Kumar, B.S. Murty, B. Sarma, S.K. Pabi, On sinterability of nanostructured W produced by high-energy ball milling, J. Mater. Res. 22 (2007) 1200-1206, https://doi.org/10.1557/jmr.2007.0166

[28] C. Wang, R. Xu, W. Tian, X. Jiang, Z. Cui, M. Wang, H. Sun, K. Fang, N. Gu, Determining intracellular temperature at single-cell level by a novel thermocouple method, Cell Res 21 (2011) 1517-1519, https://doi.org/10.1038/cr.2011.117

[29] G.M. Mikhailov, A.V. Chernykh, V.T. Petrashov, Electrical properties of epitaxial tungsten films grown by laser ablation deposition, J. Appl. Phys. 80 (1996) 948-951, https://doi.org/10.1063/1.362906

[30] Y. Qiao, J. Chen, X. Guo, D. Cantrell, R. Ruoff, J. Troy, Fabrication of nanoelectrodes for neurophysiology: cathodic electrophoretic paint insulation and focused ion beam milling, Nanotechnology 16 (2005) 1598-1602, https://doi.org/10.1088/ 0957-4484/16/9/032

[31] Y.S. Kwon, A.A. Gromov, A.P. Ilyin, A.A. Ditts, J.S. Kim, S.H. Park, M.H. Hong, Features of passivation, oxidation and combustion of tungsten nanopowders by air, Int. J. Refract. Met. Hard Mater. 22 (2004) 235-241, https://doi.org/10.1016/j. ijrmhm.2004.06.005

[32] P.K. Sahoo, S.S. Kalyan Kamal, M. Premkumar, T. Jagadeesh Kumar, B. Sreedhar, A.K. Singh, S.K. Srivastava, K. Chandra Sekhar, Synthesis of tungsten nanoparticles by solvothermal decomposition of tungsten hexacarbonyl, Int. J. Refract. Met. Hard Mater. 27 (2009) 784-791, https://doi.org/10.1016/j.ijrmhm.2009.01.005

[33] C.W. Won, H.H. Nersisyan, H.I. Won, J.H. Lee, Refractory metal nanopowders: synthesis and characterization, Curr. Opin. Solid State Mater. Sci. 14 (2010) 53-68, https://doi.org/10.1016/j.cossms.2009.10.001

[34] C. Wu, Preparation of ultrafine tungsten powders by in-situ hydrogen reduction of nano-needle violet tungsten oxide, Int. J. Refract. Met. Hard Mater. 29 (2011) 686-691, https://doi.org/10.1016/j.ijrmhm.2011.05.002

[35] H. Zhang, L. Bai, P. Hu, F. Yuan, J. Li, Single-step pathway for the synthesis of tungsten nanosized powders by RF induction thermal plasma, Int. J. Refract. Met. Hard Mater. 31 (2012) 33-38, https://doi.org/10.1016/j.ijrmhm.2011.09.002

[36] Y. Liu, K. Lan, M.H. Es-Saheb, A.A. Elzatahry, D. Zhao, Template synthesis of metal tungsten nanowire bundles with high field electron emission performance, RSC Adv. 6 (2016) 62668-62674, https://doi.org/10.1039/C6RA09308F

[37] Y.-N. Ren, M. Xia, Q.-Z. Yan, C.-C. Ge, Utilising the adsorptivity of mesoporous carbon nanotubes to prepare nanomaterials: a shape-controllable and catalystfree preparation mechanism of tungsten nanowire and nanodots, Chem. Phys. Lett. 739 (2020) 136978, https://doi.org/10.1016/j.cplett.2019.136978

[38] S. Vaddiraju, H. Chandrasekaran, M.K. Sunkara, Vapor phase synthesis of tungsten nanowires, J. Am. Chem. Soc. 125 (2003) 10792-10793, https://doi.org/10. $1021 / \mathrm{ja035868 \textrm {e }}$

[39] S. Wang, Y. He, J. Zou, Y. Jiang, J. Xu, B. Huang, C.T. Liu, P.K. Liaw, Synthesis of single-crystalline tungsten nanowires by nickel-catalyzed vapor-phase method at $850{ }^{\circ} \mathrm{C}$, J. Cryst. Growth 306 (2007) 433-436, https://doi.org/10.1016/j. jcrysgro.2007.05.043

[40] C. Wang, Y.H. He, L.Z. Hou, S.L. Wang, X.L. Liu, Q. Zhang, C.Q. Peng, Catalytic synthesis and growth mechanism of tungsten nanowire arrays on $\mathrm{SiO}_{2}$ substrates, Nano: Brief. Rep. Rev. 8 (2013) 1350010, https://doi.org/10.1142/ S1793292013500100

[41] J. Sim, J. Choi, J. Kim, Humidity sensing characteristics of focused ion beam-induced suspended single tungsten nanowire, Sens. Actuators B Chem. 194 (2014) 38-44, https://doi.org/10.1016/j.snb.2013.12.073

[42] J. Choi, J. Kim, Highly sensitive hydrogen sensor based on suspended, functionalized single tungsten nanowire bridge, Sens. Actuators B Chem. 136 (2009) 92-98, https://doi.org/10.1016/j.snb.2008.10.046

[43] J.T.L. Thong, C.H. Oon, M. Yeadon, W.D. Zhang, Field-emission induced growth of nanowires, Appl. Phys. Lett. 81 (2002) 4823-4825, https://doi.org/10.1063/1. 1529084

[44] C.H. Oon, S.H. Khong, C.B. Boothroyd, J.T.L. Thong, Characteristics of single metallic nanowire growth via a field-emission induced process, J. Appl. Phys. 99 (2006) 064309, https://doi.org/10.1063/1.2181281

[45] Z.-Q. Liu, K. Mitsuishi, K. Furuya, Effects of focus change on the fabrication of tungsten nanowire by electron-beam-induced deposition, Nanotechnology 15 (2004) S414-S419, https://doi.org/10.1088/0957-4484/15/6/019

[46] X. Yang, M.L. Simpson, S.J. Randolph, P.D. Rack, L.R. Baylor, H. Cui, W.L. Gardner, Integrated tungsten nanofiber field emission cathodes selectively grown by nanoscale electron beam-induced deposition, Appl. Phys. Lett. 86 (2005) 183106, https://doi.org/10.1063/1.1922568

[47] M. Song, K. Mitsuishi, K. Furuya, Fabrication of free-standing tungsten-nanowhiskers on $\mathrm{SiO}_{2}$ substrates with electron-beam induced deposition, Mater. Trans. 48 (2007) 2551-2555, https://doi.org/10.2320/matertrans.MD200717

[48] Y. Li, X. Li, Z.-X. Deng, B. Zhou, S. Fan, J. Wang, X. Sun, From surfactant-inorganic mesostructures to tungsten nanowires, Angew. Chem. Int. Ed. 41 (2002) 333-335, https://doi.org/10.1002/1521-3773(20020118)41:2<333::AID-ANIE333>3.0.CO;2-5

[49] A.W. Hassel, S. Milenkovic, A.J. Smith, Large scale synthesis of single crystalline tungsten nanowires with extreme aspect ratios, Phys. Status Solidi A 207 (2010) 858-863, https://doi.org/10.1002/pssa.200983319

[50] J. Gao, J. Luo, H. Geng, K. Cui, Z. Zhao, L. Liu, Morphologies, Young's modulus and resistivity of high aspect ratio tungsten nanowires, Materials 13 (2020) 3749, https://doi.org/10.3390/ma13173749
[51] D. Li, Y. Xia, Electrospinning of nanofibers: reinventing the wheel? Adv. Mater. 16 (2004) 1151-1170, https://doi.org/10.1002/adma.200400719

[52] H. Wu, W. Pan, D. Lin, H. Li, Electrospinning of ceramic nanofibers: fabrication assembly and applications, J. Adv. Ceram. 1 (2012) 2-23, https://doi.org/10.1007/ s40145-012-0002-4

[53] Y. Dai, W. Liu, E. Formo, Y. Sun, Y. Xia, Ceramic nanofibers fabricated by electrospinning and their applications in catalysis, environmental science, and energy technology, Polym. Adv. Technol. 22 (2011) 326-338, https://doi.org/10. 1002/pat.1839

[54] M.H. El-Newehy, S.S. Al-Deyab, E.-R. Kenawy, A. Abdel-Megeed, Nanospider technology for the production of nylon- 6 nanofibers for biomedical applications, J. Nanomater. 2011 (2011) 1-8, https://doi.org/10.1155/2011/626589

[55] L. Persano, A. Camposeo, C. Tekmen, D. Pisignano, Industrial upscaling of electrospinning and applications of polymer nanofibers: a review, Macromol. Mater. Eng. 298 (2013) 504-520, https://doi.org/10.1002/mame.201200290

[56] A. Greiner, J.H. Wendorff, Electrospinning: a fascinating method for the preparation of ultrathin fibers, Angew. Chem. Int. Ed. 46 (2007) 5670-5703, https:/ doi.org/10.1002/anie.200604646

[57] D. Petras, L. Mares, D. Stranska, Method and Device for Production of Nanofibers from Polymeric Solution through Electrostatic Spinning US Pat. US 2008/ 0307766A1 2008.

[58] V. Thavasi, G. Singh, S. Ramakrishna, Electrospun nanofibers in energy and environmental applications, Energy Environ. Sci. 1 (2008) 205-221, https://doi.org/ $10.1039 / \mathrm{b} 809074 \mathrm{~m}$

[59] A. Khalil, B.S. Lalia, R. Hashaikeh, M. Khraisheh, Electrospun metallic nanowires: synthesis, characterization, and applications, J. Appl. Phys. 114 (2013) 171301, https://doi.org/10.1063/1.4822482

[60] J. Shui, J.C.M. Li, Platinum nanowires produced by electrospinning, Nano Lett. 9 (2009) 1307-1314, https://doi.org/10.1021/nl802910h

[61] J.M. Kim, H.-I. Joh, S.M. Jo, D.J. Ahn, H.Y. Ha, S.-A. Hong, S.-K. Kim, Preparation and characterization of Pt nanowire by electrospinning method for methanol oxidation, Electrochim. Acta 55 (2010) 4827-4835, https://doi.org/10.1016/j. electacta.2010.03.036

[62] I. Mazurenko, M. Etienne, R. Ostermann, B.M. Smarsly, O. Tananaiko, V. Zaitsev A. Walcarius, Controlled electrochemically-assisted deposition of sol-gel biocomposite on electrospun platinum nanofibers, Langmuir 27 (2011) 7140-7147, https://doi.org/10.1021/la200069z

[63] W. Yaipimai, R. Pornprasertsuk, Fabrication of Pt, Pt-Cu, and Pt-Sn nanofibers for direct ethanol protonic ceramic fuel cell application, J. Mater. Sci. 48 (2013) 4059-4072, https://doi.org/10.1007/s10853-013-7218-8

[64] H.-W. Kim, H.-H. Lee, J.C. Knowles, Electrospinning biomedical nanocomposite fibers of hydroxyapatite/poly(lactic acid) for bone regeneration, J. Biomed. Mater. Res. A 79A (2006) 643-649, https://doi.org/10.1002/jbm.a.30866

[65] M. Bognitzki, M. Becker, M. Graeser, W. Massa, J.H. Wendorff, A. Schaper D. Weber, A. Beyer, A. Gölzhäuser, A. Greiner, Preparation of sub-micrometer copper fibers via electrospinning, Adv. Mater. 18 (2006) 2384-2386, https://doi. org/10.1002/adma.200600103

[66] H. Wu, L. Hu, M.W. Rowell, D. Kong, J.J. Cha, J.R. McDonough, J. Zhu, Y. Yang, M.D. McGehee, Y. Cui, Electrospun metal nanofiber webs as high-performance transparent electrode, Nano Lett. 10 (2010) 4242-4248, https://doi.org/10.1021/ nl102725k

[67] M. Graeser, M. Bognitzki, W. Massa, C. Pietzonka, A. Greiner, J.H. Wendorff, Magnetically anisotropic cobalt and iron nanofibers via electrospinning, Adv. Mater. 19 (2007) 4244-4247, https://doi.org/10.1002/adma.200700849

[68] H. Wu, R. Zhang, X. Liu, D. Lin, W. Pan, Electrospinning of Fe, Co, and Ni nanofibers: synthesis, assembly, and magnetic properties, Chem. Mater. 19 (2007) 3506-3511, https://doi.org/10.1021/cm070280i

[69] G. Ercolano, F. Farina, S. Cavaliere, D. Jones, J. Rozière, Nickel based electrospun materials with tuned morphology and composition, Nanomaterials 6 (2016) 236, https://doi.org/10.3390/nano6120236

[70] V. Kundrat, R. Rosentsveig, O. Brontvein, R. Tenne, J. Pinkas, Synthesis and characterization of $\mathrm{WS}_{2} / \mathrm{SiO}_{2}$ microfibers, J. Mater. Sci. 56 (2021) 10834-10846 https://doi.org/10.1007/s10853-021-05979-y

[71] M.I. Zaki, N.E. Fouad, S.A.A. Mansour, A.I. Muftah, Temperature-programmed and $\mathrm{X}$-ray diffractometry studies of hydrogen-reduction course and products of $\mathrm{WO}_{3}$ powder: Influence of reduction parameters, Thermochim. Acta 523 (2011) 90-96, https://doi.org/10.1016/j.tca.2011.05.004

[72] L. Ji, H. Cao, W. Xing, S. Liu, Q. Deng, S. Shen, Facilitating electrocatalytic hydrogen evolution via multifunctional tungsten@tungsten disulfide core-shel nanospheres, J. Mater. Chem. A 9 (2021) 9272-9280, https://doi.org/10.1039/ d1 ta01094h

[73] S. Emina, C. Altinkaya, A. Semerci, H. Okuyucu, A. Yildiz, P. Stefanov, Tungsten carbide electrocatalysts prepared from metallic tungsten nanoparticles for efficient hydrogen evolution, Appl. Catal. B: Environ. 236 (2018) 147-153, https:// doi.org/10.1016/j.apcatb.2018.05.026

[74] J. Yun, J. Hou, W. Jang, S.-Y. Kim, H. Byun, Electrospun tungsten-polyurethane composite nanofiber mats for medical radiation-shielding applications, ChemNanoMat (2021), https://doi.org/10.1002/cnma.202100387 